\title{
Best Approximation in Real Linear 2-Normed Spaces
}

\author{
R.Vijayaragavan \\ Applied Analysis Division, School of Advanced Sciences, VIT University, Vellore - 632 014, Tamilnadu, \\ India.
}

\begin{abstract}
This paper delineates existence, characterizations and strong unicity of best uniform approximations in real linear 2-normed spaces.

AMS Suject Cassification: 41A50, 41A52, 41A99, 41A28.

Key Words and Phrases: Best approximation, existence, 2-normed linear spaces.
\end{abstract}

\section{Introduction}

The concepts of linear 2-normed spaces were initially introduced by Gahler [5] in 1964. Since then many researchers (see also [2,4]) have studied the geometric structure of 2-normed spaces and obtained various results. This paper mainly deals with existence, characterizations and unicity of best uniform approximation with respect to 2-norm. Section 2 provides some important definitions and results that are used in the sequel. Some main results of the set of best uniform approximation in the context of linear 2-normed spaces are established in Section 3.

\section{Preliminaries}

Definition 2.1. Let $X$ be a linear space over real numbers with dimension greater than one and let $\mid$ ', be a real-valued function on $\mathrm{X} \times \mathrm{X}$ satisfying the following properties for all $\mathrm{x}, \mathrm{y}, \mathrm{z}$ in $\mathrm{X}$.

(i) $\|\mathrm{x}, \mathrm{y}\|=0$ if and only if $\mathrm{x}$ and $\mathrm{y}$ are linearly dependent,

(ii) $\|\mathrm{x}, \mathrm{y}\|=\|\mathrm{y}, \mathrm{x}\|$,

(iii) $\|\alpha x, y\|=|\alpha|\|x, y\|$, where $\alpha$ is a real number,

(iv) $\|\mathrm{x}, \mathrm{y}+\mathrm{z}\| \leq\|\mathrm{x}, \mathrm{y}\|+\|\mathrm{x}, \mathrm{z}\|$.

Then $\|, \cdot\|$ is called a 2-norm and the linear space $X$ equipped with 2-norm is called a linear 2normed space. It is clear that 2-norm is non-negative.

Example 2.2. Let $X=\mathrm{R}^{3}$ with usual component wise vector additions and scalar multiplications. For $\mathrm{x}=\left(\mathrm{a}_{1}, \mathrm{~b}_{1}, \mathrm{c}_{1}\right)$ and $\mathrm{y}=\left(\mathrm{a}_{2}, \mathrm{~b}_{2}, \mathrm{c}_{2}\right)$ in $\mathrm{X}$, define

$\|x, y\|=\max \left\{\left|a_{1} b_{2}-a_{2} b_{1}\right|,\left|b_{1} c_{2}-b_{2} c_{1}\right|,\left|a_{1} c_{2}-a_{2} c_{1}\right|\right\}$.

Then clearly $\|, \cdot\|$ is a 2-norm on $\mathrm{X}$.

Definition 2.3. Let $G$ be a subset of a real linear 2-normed space $X$ and $x \in X$. Then $g_{0} \in G$ is said to be a best approximation to $x$ from the elements of $G$ if

$\left.\left\|\mathrm{x}-\mathrm{g}_{0}, \mathrm{z}\right\|=\inf \|\mathrm{x}-\mathrm{g}, \mathrm{z}\|, \mathrm{z} \in \mathrm{X} \backslash \mathrm{V}, \mathrm{G}\right)$

$\mathrm{g} \in \mathrm{G}$

where $V(x, G)$ is the subspace generated by $x$ and $G$.

The set of all elements of best approximation to $\mathrm{x} \in \mathrm{X}$ from $\mathrm{G}$ with respect to the set $\mathrm{z}$ is denoted by $\mathrm{P}_{\mathrm{G}, \mathrm{Z}}(\mathrm{x})$.

Definition 2.4. A linear 2-normed space (X, $\|, \cdot$,$\| ) is said to be strictly convex if$ $\|\mathrm{a}+\mathrm{b}, \mathrm{c}\|=\|\mathrm{a}, \mathrm{c}\|+\|\mathrm{b}, \mathrm{c}\|,\|\mathrm{a}, \mathrm{c}\|=\|\mathrm{b}, \mathrm{c}\|=1$ and $\mathrm{c} \notin \mathrm{V}(\mathrm{a}, \mathrm{b}) \Rightarrow \mathrm{a}=\mathrm{b}$. or 
A linear 2-normed space $(\mathrm{X},\|, \cdot\| \|)$ is said to be strictly convex if and only if

$$
\|\mathrm{x}, \mathrm{z}\|=\|\mathrm{y}, \mathrm{z}\|=1, \mathrm{x} \neq \mathrm{y} \text { and } \mathrm{z} \in \mathrm{X} \mid \mathrm{V}(\mathrm{x}, \mathrm{y}) \Rightarrow\left\|\frac{1}{2}(x+y), z\right\|<1
$$

Example 2.5. Let $\mathrm{X}=\mathrm{R}^{3}$ with 2-norm defined as follows: For $\mathrm{x}=\left(\mathrm{a}_{1}, \mathrm{~b}_{1}, \mathrm{c}_{1}\right)$ and $\mathrm{y}=\left(\mathrm{a}_{2}, \mathrm{~b}_{2}, \mathrm{c}_{2}\right)$ in $\mathrm{X}$, let

$$
\|x, y\|=\left\{\left(a_{1} b_{2}-a_{2} b_{1}\right)^{2}+\left(b_{1} c_{2}-b_{2} c_{1}\right)^{2}+\left(a_{1} c_{2}-a_{2} c_{1}\right)^{2}\right\}^{\frac{1}{2}}
$$

Then the space $(X,\|.,\|$.$) is strictly convex linear 2-normed space.$

Definition 2.6. For all functions $\mathrm{h} \in \mathrm{C}([\mathrm{a}, \mathrm{b}] \times[\mathrm{c}, \mathrm{d}])$

$\|\mathrm{h}\| \infty=\left\{\sup \left|\mathrm{h}\left(\mathrm{t}, \mathrm{t}^{\prime}\right)\right|: \mathrm{t} \in[\mathrm{a}, \mathrm{b}], \mathrm{t}^{\prime} \in[\mathrm{c}, \mathrm{d}]\right\}$.

The set of extreme points of a function $h \in C([a, b] \times[c, d])$ is defined by $E(h)=\{x \in[a, b], y$ $\in[c, d]:|h(x, y)|=\|h\| \infty\}$. Best approximation with respect to this norm is called best uniform approximation.

Definition 2.7. Let $\mathrm{G}$ be a subspace of $\mathrm{C}([\mathrm{a}, \mathrm{b}] \times[\mathrm{c}, \mathrm{d}])=\{\mathrm{f}:[\mathrm{a}, \mathrm{b}] \times[\mathrm{c}, \mathrm{d} \boldsymbol{\longrightarrow} \mathbf{R}$

A function $\mathrm{g}_{0} \in \mathrm{G}$ is called a strongly unique best uniform approximation of $\mathbf{f} \in \mathrm{C}([\mathrm{a}, \mathrm{b}] \times[\mathrm{c}, \mathrm{d}])$ if there exists a constant $\mathrm{kf}>0$ such that for all $\mathrm{g} \in \mathrm{G}$, $\|\mathbf{f}-\mathrm{g}\| \infty \geq\left\|\mathbf{f}-\mathrm{g}_{0}\right\| \infty+\mathrm{k}_{\mathbf{f}}\left\|\mathrm{g}-\mathrm{g}_{0}\right\| \infty$.

Example 2.8. Consider the space $\mathrm{G}=\operatorname{span}\left\{\mathrm{g}_{1}\right\}$ of $\mathrm{C}([-1,1] \times[-1,1])$, where $\mathrm{g}_{1}\left(\mathrm{t}, \mathrm{t}^{*}\right)=\mathrm{t} \in[-1$, 1] and $\mathbf{f} \in(\mathrm{C}[-1,1] \times[-1,1])$. Then $(0,1)$ is the best approximation of $[1,1]$.

Definition 2.9. Let $G$ be a subset of $C([a, b] \times[c, d])$ and let $f \in C([a, b] \times[c, d])$ have a unique best uniform approximation $\mathrm{g}_{0} \in \mathrm{G}$. Then the projection $\mathrm{P}_{\mathrm{G}} \quad \mathrm{C}([\mathrm{a}, \mathrm{b}] \times[\mathrm{c}, \mathrm{d}]) \rightarrow \mathrm{POW}(\mathrm{G})$ is called Lipchitz-continuous at $\mathbf{f}$ if there exists a const $\mathrm{k}_{\mathbf{f}}>0$ such that for all $\overline{\mathrm{f}} \in \mathrm{C}([\mathrm{a}, \mathrm{b}] \times[\mathrm{c}, \mathrm{d}])$ and all $\mathrm{g} \overline{\mathbf{f}} \in$ $\mathrm{P}_{\mathrm{G}}(\overline{\mathbf{f}}),\left\|\mathrm{g}_{\mathbf{f}}-\mathrm{g}_{\overline{\mathbf{f}}}\right\| \infty \leq \mathrm{k}_{\mathbf{f}}\|\mathbf{f}-\overline{\mathbf{f}}\| \infty$.

\section{Main Results}

Theorem 3.1. Let $\mathrm{G}$ be a finite-dimensional subspace of a real linear 2-normed space $X$. Then for every $\mathrm{x} \in \mathrm{X}$, there exists a best approximation from $\mathrm{G}$. Proof.

Let $\mathrm{x} \in \mathrm{X}$.

Then by the definition of the infimum there exists a sequence $\left\{g_{n}\right\} \in G$ such that $\left\|x-g_{n}, z\right\| \rightarrow \inf _{g \in G}\|x-g, z\|$.

This implies that there exists a constant $\mathrm{k}>0$ such that for all $\mathbf{n}$,

$$
\begin{gathered}
\left\|g_{n}, z\right\|-\|x, z\| \leq\left\|x-g_{n}, z\right\| \leq \inf _{g \in G}\|x-g, z\|+k \\
\leq\|x, z\|+k
\end{gathered}
$$

Hence for all $\mathrm{n},\left\|\mathrm{g}_{\mathbf{n}}, \mathrm{z}\right\| \leq 2\|\mathrm{x}, \mathrm{z}\|+\mathrm{k}$.

$\Rightarrow\left\{g_{n}\right\}$ is bounded sequence. Then $t h e r e$ exists a subsequence $\left\{g_{n k}\right\}$ of $\left\{g_{n}\right\}$ converging to $\mathrm{g}_{0} \in \mathrm{G}$. 


$$
\begin{aligned}
& \therefore\left\|x-g_{0}, z\right\|=\lim _{k \rightarrow \infty}\left\|x-g_{n_{k}}\right\|=\inf _{g \in G}\|x-g, z\|, z \in X \backslash V(x, G) \\
& \quad \Rightarrow \mathrm{g}_{0} \in \mathrm{PG}_{\mathrm{G}, \mathrm{Z}}(\mathrm{x}), \text { which completes the proof. }
\end{aligned}
$$

Theorem 3.2. Let $\mathrm{G}$ be a finite -dimensional subspace of a strictly convex linear 2- normed space $\mathrm{X}$. Then for every $x \in X$, there exists a unique best approximation from $\mathrm{G}$.

Proof. Let $x \in X$. Since $\mathrm{G}$ is a finite-dimensional, by Theorem 3.1 there exists an element $g_{0} \in G$ Such that , $\mathrm{g}_{0} \in \mathrm{P}_{\mathrm{G}, \mathrm{Z}}(\mathrm{x}), z \in X \backslash V(x, G)$.

Now we show that, $P_{G, Z}(x)=\left\{g_{0}\right\}$. For that first we prove that $P_{G, Z}(x)$ is convex. Let $g_{1}, g_{2} \in$ $\mathrm{PG}_{\mathrm{Z}}(\mathrm{x})$ and $0 \leq \alpha \leq 1$. Then,

$$
\begin{aligned}
& \left\|\mathrm{x}-\left(\alpha \mathrm{g}_{1}+(1-\alpha) \mathrm{g}_{2}\right), \mathrm{z}\right\|=\left\|\alpha\left(\mathrm{x}-\mathrm{g}_{1}\right)+(1-\alpha)\left(\mathrm{x}-\mathrm{g}_{2}\right), \mathrm{z}\right\| \\
& \begin{aligned}
\leq \alpha \| & \mathrm{x}-\mathrm{g}_{1}, \mathrm{z}\|+(1-\alpha)\| \mathrm{x}-\mathrm{g}_{2}, \mathrm{z} \| \\
& =\alpha \inf _{g \in G}\|x-g, z\|+(1-\alpha) \inf _{g \in G}\|x-g, z\| \\
& =\inf _{g \in G}\|x-g, z\| \\
& \leq\|x-g, z\|, \text { for all } g \in G .
\end{aligned}
\end{aligned}
$$

Since $\alpha \mathrm{g}_{1}+(1-\alpha) \mathrm{g}_{2} \in \mathrm{G}, \alpha \mathrm{g}_{1}+(1-\alpha) \mathrm{g}_{2} \in \mathrm{P}_{\mathrm{G}, \mathrm{Z}}(\mathrm{x})$. We shall suppose that $\mathrm{g}^{*} \in \mathrm{PG}_{\mathrm{G}, \mathrm{Z}}(\mathrm{x})$. Then ${ }^{1}\left(\mathrm{~g} 0+\mathrm{t}^{*}\right) \in \mathrm{PG}_{\mathrm{G}, \mathrm{Z}}(\mathrm{x})$, which implies that

$$
\begin{gathered}
\left\|\frac{1}{2}\left\{\left(x-g_{0}\right)+\left(x-g^{*}\right)\right\}, z\right\|=\left\|x-\frac{1}{2}\left(g_{0}-g^{*}\right), z\right\| \\
=\inf _{g \in G}\|x-g, z\|_{1}
\end{gathered}
$$

Since $\left\|x-g_{0}, z\right\|=\left\|x-g^{*}, z\right\|=\inf \|x-g, z\|$ and $X$ is strictly convex, we obtain

$$
\mathrm{g} \in \mathrm{G}
$$

$\mathrm{x}-\mathrm{g}_{0}=\mathrm{x}-\mathrm{g}^{*} \Rightarrow \mathrm{g}_{0}=\mathrm{g}^{*}$. This proves that $\mathrm{PG}_{\mathrm{G}} \mathrm{Z}(\mathrm{x})=\left\{\mathrm{g}_{0}\right\}$.

Theorem 3.3. Let $\mathrm{G}$ be a finite-dimensional subspace of a real linear 2-normed space $\mathrm{X}$ with the property that every function with domain $\mathrm{X} \times \mathrm{X} h$ as a unique best approximation from $\mathrm{G}$. Then for all $\mathrm{f}_{1}, \mathrm{f}_{2} \in \mathrm{X} \times \mathrm{X}$,

$$
\mid \inf _{g \in G}\left\|f_{1}-g, z\right\|-\inf _{g \in G}\left\|f_{2}-g, z\right\| \leq\left\|f_{1}-f_{2}, z\right\|, z \in X \backslash G \text { and } P_{G}: X \times X \rightarrow G \text { is continuous.Proof. }
$$

Suppose that $\mathrm{PG}_{\mathrm{G}}$ is not continuous. Then there exists an element $\mathrm{f} \in \mathrm{X} \times \mathrm{X}$

and a sequence $\left\{f_{n}\right\} \in X \times X$ such that $\left\{f_{n} \times g_{n}\right\}$.

$\mathrm{P}_{\mathrm{G}, \mathrm{Z}}\left(\mathbf{f}_{\mathbf{n}}\right)$ does not converge to $\mathrm{P}_{\mathrm{G}}(\mathbf{f})$. Since $\mathrm{G}$ is finite dimensional, there ex-ists a subsequence $\quad\left\{\mathbf{f}_{\mathrm{nk}}\right\} \quad$ of $\quad\left\{\mathbf{f}_{\mathbf{n}}\right\}$ such that $\mathrm{P}_{\mathrm{G}, \mathrm{Z}}\left(\mathbf{f}_{\mathrm{nk}}\right) \rightarrow g_{0} \in \mathrm{G}, \mathrm{g}_{0} \neq$ $\mathrm{P}_{\mathrm{G}}(\mathrm{f})$ and we shall show that the mapping

$$
f \rightarrow \inf _{g \in G}\|f-g, z\| \text { is continuous }(f \in X \times X)
$$

Let $f_{1}, f_{2} \in X \times X$. Then there exists a $g_{2} \in G$ such that

$$
\left\|\mathrm{f}_{2}-\mathrm{g} 2, \mathrm{z}\right\|=\inf \left\|\mathrm{f}_{2}-\mathrm{g}, \mathrm{z}\right\|
$$




$$
\begin{aligned}
& \Rightarrow \inf _{\mathrm{g} \in \mathrm{G}}\left\|\mathbf{f}_{1}-\mathrm{g}, \mathrm{z}\right\| \leq\left\|\mathbf{f}_{1}-\mathrm{g}_{2}, \mathrm{z}\right\| \\
& \leq\left\|\mathbf{f}_{1}-\mathbf{f}_{2}, \mathrm{z}\right\|+\left\|\mathbf{f}_{2}-\mathrm{g}_{2}, \mathrm{z}\right\| \\
& =\left\|f_{1}-f_{2}, z\right\|+\inf _{g \in G}\left\|f_{2}-g, z\right\| \\
& \Rightarrow \inf \left\|\mathbf{f}_{1}-\mathrm{g}, \mathrm{z}\right\|-\inf \left\|\mathbf{f}_{2}-\mathrm{g}, \mathrm{z}\right\| \leq\left\|\mathbf{f}_{1}-\mathbf{f}_{2}, \mathrm{z}\right\|, \mathrm{z} \in \mathrm{X} \backslash \mathrm{G} . \\
& \mathrm{g} \in \mathrm{G}
\end{aligned}
$$

This proves that

$\mathrm{g} \in \mathrm{G}$

$$
\inf _{g \in G}\left\|f_{1}-g, z\right\|-\inf _{g \in G}\left\|f_{2}-g, z\right\| \leq\left\|f_{1}-f_{2}, z\right\|, z \in X \backslash G
$$

By continuity it follows that

$$
\begin{aligned}
& \left\|\mathbf{f}_{\mathbf{n k}}-\mathrm{PG}_{\mathbf{G}}\left(\mathbf{f}_{\mathbf{n k}}\right), \mathrm{z}\right\|=\inf \left\|\mathbf{f}_{\mathbf{n k}}-\mathrm{g}, \mathrm{z}\right\| \\
& \quad \rightarrow \inf _{g \in G} \lim _{k \rightarrow \infty}\left\|f_{n_{k}}-g, z\right\| \\
& =\inf _{g \in G}\|f-g, z\|
\end{aligned}
$$

and $\lim \left\|f_{n_{k}}-P_{G}\left(f_{n_{k}}\right), z\right\| \rightarrow\left\|f-g_{0}, z\right\|$

$$
\Rightarrow \| \lim \left(f_{n_{k}}-P_{G}\left(f_{n_{k}}\right), z\|=\| f-P_{G}(f), z \|\right.
$$

$\Rightarrow g_{0}$ and $P_{G}(f)$ are two distinct best approximation of $f$ and $\mathrm{G}$ which contradicts the uniqueness of best approximation.

Therefore $P_{G}: X \times X \rightarrow G$ is continuous.

A 2 -functional is a real valued mapping with domain $A \times C$ with A and $\mathrm{C}$ are linear manifolds of a 2- normed space $\mathrm{X}$.

A linear 2- functionals is 2- functional such that

(i) $F(a+c, b+d)=F(a, b)+F(a, d)+F(c, b)+F(c, d)$

(ii) $F(\alpha a, \beta b)=\alpha \beta F(a, b)$.

$\mathrm{F}$ is called a bounded 2-functional if there is a real constant $k \geq 0$ such that $|F(a, b)| \leq k\|a, b\|$ for all a,b in the domain of $\mathrm{F}$ and

$$
\begin{aligned}
\|F\| & =\inf \{k:|f(a, b)| \leq k\|a, b\|,(a, b \in D(F)\} \\
& =\sup \{f(a, b):\|a, b\|=1,(a, b) \in D(F)\}
\end{aligned}
$$




$$
=\sup \left\{\frac{|f(a, b)|}{\|a, b\|}:\|a, b\| \neq 0,(a, b) \in D(F)\right\}
$$

Theorem 3.4. Let $\mathrm{G}$ be a subspace of $\mathrm{C}([\mathrm{a}, \mathrm{b}] \times[\mathrm{a}, \mathrm{b}]), \mathrm{f} \in \mathrm{C}([\mathrm{a}, \mathrm{b}] \times[\mathrm{a}, \mathrm{b}])$ and $\mathrm{g}_{0} \in \mathrm{G}$. Then the following statements are equivalent:

(i) The function $g_{0}$ is a best uniform approximation of $\mathbf{f}$ from $\mathrm{G}$. (ii) For every function $\mathrm{g} \in \mathrm{G}$, $\min$

$\left.\mathbf{t}, \mathbf{t}^{*} \in \mathrm{E}(\mathbf{f}-\mathrm{g} 0) \mathbf{f}\left(\mathrm{t}, \mathrm{t}^{*}\right)-\mathrm{g}_{0}\left(\mathrm{t}, \mathrm{t}^{*}\right)\right)\left(\mathrm{g}\left(\mathrm{t}, \mathrm{t}^{*}\right)\right) \leq 0$

Proof. (ii) $\Rightarrow$ (i). Suppose that (ii) holds and let $g \in G$. Then by (ii) there exist the points $t, t^{\prime} \in E$ (f $-\mathrm{g}_{0}$ ) such that

$\left(\mathbf{f}\left(\mathrm{t}, \mathrm{t}^{*}\right)-\mathrm{g}_{0}\left(\mathrm{t}, \mathrm{t}^{*}\right)\right)\left(\mathrm{g}\left(\mathrm{t}, \mathrm{t}^{*}\right)-\mathrm{g}_{0}\left(\mathrm{t}, \mathrm{t}^{*}\right)\right) \leq 0$.Then we have

$\|\mathbf{f}-\mathrm{g}\| \infty \geq\left|\mathbf{f}\left(\mathrm{t}, \mathrm{t}^{*}\right)-\mathrm{g}\left(\mathrm{t}, \mathrm{t}^{*}\right)\right|$

$=\left|\mathbf{f}\left(\mathrm{t}, \mathrm{t}^{*}\right)-\mathrm{g}_{0}\left(\mathrm{t}, \mathrm{t}^{*}\right)+\mathrm{g}_{0}\left(\mathrm{t}, \mathrm{t}^{*}\right)-\mathrm{g}\left(\mathrm{t}, \mathrm{t}^{*}\right)\right|$

$=\left|\mathbf{f}\left(\mathrm{t}, \mathrm{t}^{*}\right)-\mathrm{g}_{0}\left(\mathrm{t}, \mathrm{t}^{*}\right)\right|+\left|\mathrm{g}\left(\mathrm{t}, \mathrm{t}^{*}\right)-\mathrm{g}_{0}\left(\mathrm{t}, \mathrm{t}^{*}\right)\right|$

$\geq\left\|\mathbf{f}\left(\mathrm{t}, \mathrm{t}^{*}\right)-\mathrm{g}_{0}\left(\mathrm{t}, \mathrm{t}^{*}\right)\right\| \infty$

which shows that (i) holds.

(i) $\Rightarrow$ (ii). Suppose that (i) holds and assume that (ii) fails. Then there exists a function $g_{1} \in \mathrm{G}$ such that for all $\mathrm{t}, \mathrm{t}^{*} \in \mathrm{E}\left(\mathrm{f}-\mathrm{g}_{0}\right),\left(\mathrm{f}\left(\mathrm{t}, \mathrm{t}^{*}\right)-\mathrm{g}_{0}\left(\mathrm{t}, \mathrm{t}^{*}\right)\right) \mathrm{g}_{1}\left(\mathrm{t}, \mathrm{t}^{*}\right)>0$. Since $\mathrm{E}\left(\mathrm{f}-\mathrm{g}_{0}\right)$ is compact, there exists a real number $\mathrm{c}>0$ such that for all $\mathrm{t}, \mathrm{t}^{*} \in \mathrm{E}\left(\mathrm{f}-\mathrm{g}_{0}\right)$

$\left(\mathbf{f}\left(\mathrm{t}, \mathrm{t}^{*}\right)-\mathrm{g}_{0}\left(\mathrm{t}, \mathrm{t}^{*}\right) \mathrm{g}_{1}\left(\mathrm{t}, \mathrm{t}^{*}\right)>\mathrm{c}\right.$.

Further, there exists an open neighborhood $U$ of $E\left(f-g_{0}\right)$ such that for all

$\mathrm{t}, \mathrm{t}^{*} \in \mathrm{U}, \operatorname{and}_{\mathrm{c}}\left(\mathbf{f}\left(\mathrm{t}, \mathbf{t}^{*}\right)-\mathrm{g}_{0}\left(\mathrm{t}, \mathbf{t}^{*}\right)\right) \mathrm{g} 1\left(\mathrm{t}, \mathrm{t}^{*}\right)>2$

$\left|\mathbf{f}\left(\mathrm{t}, \mathrm{t}^{*}\right)-\mathrm{g}_{0}\left(\mathrm{t}, \mathrm{t}^{*}\right)\right| \geq_{2}\left\|\mathbf{f}-\mathrm{g}_{0}\right\| \infty$

Since $[a, b] \| U$ is compact, there exists a real number $d>0 \mathrm{such}$ that for all $\mathrm{t}, \mathrm{t}^{*} \in[\mathrm{a}, \mathrm{b}] \mathrm{U}$,

$\left|\mathbf{f}\left(\mathrm{t}, \mathrm{t}^{*}\right)-\mathrm{g}_{0}\left(\mathrm{t}, \mathrm{t}^{*}\right)\right|<\left\|\mathrm{f}-\mathrm{g}_{0}\right\| \infty_{-\mathrm{d}} \quad$ (4) Now we shall assume that

$\left\|\mathrm{g}_{1}\right\| \infty \leq \min \left\{\mathrm{d},\left\|\mathrm{f}-\mathrm{g}_{0}\right\|\right\}$.

Let $\mathrm{g}_{2}=\mathrm{g}_{0}+\mathrm{g}_{1}$. Then by (4) and (5) for all $\mathrm{t}, \mathrm{t}^{*} \in[\mathrm{a}, \mathrm{b}] \backslash \mathrm{U}$,

$$
\begin{aligned}
& \left|\mathbf{f}\left(\mathrm{t}, \mathrm{t}^{*}\right)-\mathrm{g}_{2}\left(\mathrm{t}, \mathrm{t}^{*}\right)\right|=\left|\left(\mathbf{f}\left(\mathrm{t}, \mathrm{t}^{*}\right)-\mathrm{g}_{0}\left(\mathrm{t}, \mathrm{t}^{*}\right)\right)-\mathrm{g}_{1}\left(\mathrm{t}, \mathrm{t}^{*}\right)\right| \\
& \leq\left|\mathbf{f}\left(\mathrm{t}, \mathrm{t}^{*}\right)-\mathrm{g}_{0}\left(\mathrm{t}, \mathrm{t}^{*}\right)\right|+\left|\mathrm{g}_{1}\left(\mathrm{t}, \mathrm{t}^{*}\right)\right| \\
& \leq\left\|\mathbf{f}\left(\mathrm{t}, \mathrm{t}^{*}\right)-\mathrm{g}_{0}\left(\mathrm{t}, \mathrm{t}^{*}\right)\right\| \infty-\mathrm{d}+\left\|\mathrm{g}_{1}\left(\mathrm{t}, \mathrm{t}^{*}\right)\right\| \\
& \quad \leq\left\|\mathbf{f}\left(\mathrm{t}, \mathrm{t}^{*}\right)-\mathrm{g}_{0}\left(\mathrm{t}, \mathrm{t}^{*}\right)\right\| \infty .
\end{aligned}
$$


For all $\mathrm{t} \in \mathrm{U}$, by (2), (3) and (5),

$$
\begin{aligned}
& \left|\mathbf{f}\left(\mathrm{t}, \mathrm{t}^{*}\right)-\mathrm{g}_{2}\left(\mathrm{t}, \mathrm{t}^{*}\right)\right|=\left|\left(\mathbf{f}\left(\mathrm{t}, \mathrm{t}^{*}\right)-\mathrm{g}_{0}\left(\mathrm{t}, \mathrm{t}^{*}\right)\right)-\mathrm{g}_{1}\left(\mathrm{t}, \mathrm{t}^{*}\right)\right| \\
& \leq\left|\mathbf{f}\left(\mathrm{t}, \mathrm{t}^{*}\right)-\mathrm{g}_{0}\left(\mathrm{t}, \mathrm{t}^{*}\right)\right|-\left|\mathrm{g}_{1}\left(\mathrm{t}, \mathrm{t}^{*}\right)\right| \\
& \leq\left\|\mathbf{f}-\mathrm{g}_{0}\right\| \infty \\
& \Rightarrow\left\|\mathbf{f}-\mathrm{g}_{2}\right\| \infty \leq\left\|\mathbf{f}-\mathrm{g}_{0}\right\| \infty
\end{aligned}
$$

$\Rightarrow \mathrm{g}_{0}$ is not the best uniform approximation of $\mathbf{f}$ which is a contradiction. Hence the proof.

Theorem 3.5. Let $\mathrm{G}$ be a subset of $\mathrm{C}([\mathrm{a}, \mathrm{b}] \times[\mathrm{c}, \mathrm{d}])$ and $\mathbf{f}$ has a strongly unique best uniform approximation from $\mathrm{G}$, then

$P_{G}: C([a, b] \times[c, b]) P O W(G)$ is Lipschitz-continuous at $\mathrm{f}$.

Proof. Let $f \in X=C([a, b] \times[c, b])$ have a strongly unique best uniform approximation $g_{f} \in G$ . Then there exists $\mathrm{kf}_{\mathbf{f}}>0$ such that for all $\mathrm{g} \in \mathrm{G}$.

$\|\mathbf{f}-\mathrm{g}\| \infty \geq\left\|\mathbf{f}-\mathrm{g}_{\mathbf{f}}\right\| \infty+\mathrm{k}_{\mathbf{f}}\left\|\mathrm{g}-\mathrm{g}_{\mathbf{f}}\right\| \infty$

Then for all

$\tilde{\mathbf{f}} \in X$ and for all $g_{\tilde{\mathbf{f}}} \in P_{G}(\tilde{\mathbf{f}})$.

We obtain $\mathrm{k} \mathbf{f}\left\|\mathrm{g}_{\mathbf{f}}-\mathrm{g}_{\mathbf{f}}\right\| \infty \leq\left\|\mathbf{f}-\mathrm{g}_{\tilde{\mathbf{f}}}\right\| \infty-\left\|\mathbf{f}-\mathrm{g}_{\mathbf{f}}\right\| \infty$

$\leq\|\mathbf{f}-\tilde{\mathbf{f}}\| \infty+\left\|\tilde{\mathbf{f}}-\mathrm{g}_{\tilde{\mathbf{f}}} \tilde{\mathbf{f}}\right\| \infty-\left\|\mathbf{f}-\mathrm{g}_{\mathbf{f}}\right\| \infty$

$\leq\|\mathbf{f}-\tilde{\mathbf{f}}\| \infty+\|\mathbf{f}-\tilde{\mathbf{f}}\| \infty=2\|\mathbf{f}-\tilde{\mathbf{f}}\| \infty . \Rightarrow L_{f}=\frac{2}{k_{f}}$ is the desired constant.

Theorem 3.6. Let $\mathrm{G}$ be a finite dimensional subspace of $\mathrm{X}=\mathrm{C}([\mathrm{a}, \mathrm{b}] \times[\mathrm{c}, \mathrm{d}])$, $f \in X \backslash G$ and $g_{0} \in G$. Then the following statements are equivalent:

(i) The function $\mathrm{g}_{0}$ is a strongly unique best uniform approximation of $\mathbf{f}$ from

G .

(ii) For every nontrivial function $g \in G$,

$\min$

$\mathrm{x}, \mathrm{y} \in \mathrm{E}(\mathrm{f}-\mathrm{g} 0)(\mathrm{f}(\mathrm{x}, \mathrm{y})-\mathrm{g} 0(\mathrm{x}, \mathrm{y})) \mathrm{g}(\mathrm{x}, \mathrm{y})<0$

(iii) There exists a constant $\mathrm{k}_{\mathbf{f}}>0$ such that for every function $\mathrm{g} \in \mathrm{G}$, $\min$

$\mathrm{x}, \mathrm{y} \in \mathrm{E}(\mathbf{f}-\mathrm{g} 0)\left(\mathrm{f}(\mathrm{x}, \mathrm{y})-\mathrm{g}_{0}(\mathrm{x}, \mathrm{y})\right) \mathrm{g}(\mathrm{x}, \mathrm{y}) \leq-\mathrm{k}_{\mathbf{f}}\left\|\mathbf{f}-\mathrm{g}_{0}\right\| \infty \boldsymbol{g} \| \infty$

Proof. (iii) $\Rightarrow$ (i). We shall suppose that (iii) holds and let $g \in G$. Then by (iii) there exist the points $\mathrm{x}, \mathrm{y} \in \mathrm{E}\left(\mathrm{f}-\mathrm{g}_{0}\right)$ such that

$\left(\mathrm{f}(\mathrm{x}, \mathrm{y})-\mathrm{g}_{0}(\mathrm{x}, \mathrm{y})\right)\left(\mathrm{g}(\mathrm{x}, \mathrm{y})-\mathrm{g}_{0}(\mathrm{x}, \mathrm{y})\right) \leq-\mathrm{kf}_{\mathbf{f}}\left\|\mathbf{f}-\mathrm{g}_{0}\right\| \infty \boldsymbol{}_{\infty}\left\|\mathrm{g}-\mathrm{g}_{0}\right\| \infty$. This implies that

$$
\begin{aligned}
& \|\mathbf{f}-\mathrm{g}\| \quad \infty \geq|\mathbf{f}(\mathrm{x}, \mathrm{y})-\mathrm{g}(\mathrm{x}, \mathrm{y})| \\
& =\left|\mathbf{f}(\mathrm{x}, \mathrm{y})-\mathrm{g}_{0}(\mathrm{x}, \mathrm{y})-\left(\mathrm{g}(\mathrm{x}, \mathrm{y})-\mathrm{g}_{0}(\mathrm{x}, \mathrm{y})\right)\right| \\
& =\left|\mathbf{f}(\mathrm{x}, \mathrm{y})-\mathrm{g}_{0}(\mathrm{x}, \mathrm{y})\right|+\left|\mathrm{g}(\mathrm{x}, \mathrm{y})-\mathrm{g}_{0}(\mathrm{x}, \mathrm{y})\right| \geq\left\|\mathbf{f}-\mathrm{g}_{0}\right\| \infty+\frac{k_{f}\left\|f-g_{0}\right\|_{\infty}\left\|g-g_{0}\right\|_{\infty}}{\left|f(x, y)-g_{0}(x, y)\right|}
\end{aligned}
$$


$=\left\|\mathbf{f}-\mathrm{g}_{0}\right\| \infty+\mathrm{k}_{\mathbf{f}}\left\|\mathrm{g}-\mathrm{g}_{0}\right\| \infty$.

(i) $\Rightarrow$ (iii). Suppose that (iii) fails, i.e. there exists a function $\mathrm{g}_{1} \in \mathrm{G}$ such that for all $\mathrm{x}, \mathrm{y} \in \mathrm{E}\left(\mathrm{f}-\mathrm{g}_{0}\right.$ ),

$\left(\mathbf{f}(\mathrm{x}, \mathrm{y})-\mathrm{g}_{0}(\mathrm{x}, \mathrm{y})\right) \mathrm{g}_{1}(\mathrm{x}, \mathrm{y})>-\mathrm{k}_{\mathbf{f}}\left\|\mathbf{f}-\mathrm{g}_{0}\right\| \infty\left\|\mathrm{g}_{1}\right\| \infty$.

Since $E\left(f-g_{0}\right)$ is compact, there exists an open neighborhood $U$ of $E\left(f-g_{0}\right)$

such that for all $x, y \in U$

$\left(\mathrm{f}(\mathrm{x}, \mathrm{y})-\mathrm{g}_{0}(\mathrm{x}, \mathrm{y})\right)_{1}(\mathrm{x}, \mathrm{y})>-\mathrm{k}_{\mathbf{f}}\left\|\mathrm{f}-\mathrm{g}_{0}\right\| \infty\left\|\mathrm{g}_{1}\right\| \infty$

and

1

$\left|\mathrm{f}(\mathrm{x}, \mathrm{y})-\mathrm{g}_{0}(\mathrm{x}, \mathrm{y})\right| \geq_{2}\left\|\mathrm{f}-\mathrm{g}_{0}\right\| \infty$.

Further, we can choose $U$ sufficiently small such that for all $x, y \in U$ with $\left(\mathrm{f}(\mathrm{x}, \mathrm{y})-\mathrm{g}_{0}(\mathrm{x}, \mathrm{y})\right) \mathrm{g}_{1}(\mathrm{x}, \mathrm{y})<0$

$\left|\mathrm{g}_{1}(\mathrm{x}, \mathrm{y})\right|<\mathrm{k}_{\mathbf{f}}\left\|\mathrm{g}_{1}\right\| \infty$.

(7) Since $[a, b] \times[c, d] \cup U$ is compact, there exists a real

number $\mathrm{c}>0$ such that for all

$\mathrm{x}, \mathrm{y} \in[\mathrm{a}, \mathrm{b}] \times[\mathrm{c}, \mathrm{d}]] \mathrm{U}$,

$\left|f(x, y)-g_{0}(x, y)\right| \leq\left\|f-g_{0}\right\| \infty^{-c}$.

We may assume that without loss of generality

$\left\|{ }^{\mathrm{g}} 1\right\| \infty \leq \min \left\{c, \frac{1}{2}\left\|f-g_{0}\right\|_{\infty}\right\}$

Let $\mathrm{g}_{2}=\mathrm{g}_{0}+\mathrm{g}_{1}$. Then by (8) and (9) for all $\mathrm{x}, \mathrm{y} \in[\mathrm{a}, \mathrm{b}] \times[\mathrm{c}, \mathrm{d}] \mathrm{U}$,

$\left|f(x, y)-g_{2}(x, y)\right|=\left|f(x, y)-g_{0}(x, y)-g_{1}(x, y)\right|$

$\leq\left\|\mathbf{f}-\mathrm{g}_{0}\right\| \infty-\mathrm{c}+\left\|\mathrm{g}_{1}\right\| \infty$

$$
\leq\left\|\mathbf{f}-\mathrm{g}_{0}\right\| \infty \text {. }
$$

Again, by (6) and (7), for all $x, y \in U$ with

$\left(\mathrm{f}(\mathrm{x}, \mathrm{y})-\mathrm{g}_{0}(\mathrm{x}, \mathrm{y})\right)_{1}(\mathrm{x}, \mathrm{y})<0$

$\left|f(x, y)-g_{2}(x, y)\right|=\left|\left(f(x, y)-g_{0}(x, y)\right)-g_{1}(x, y)\right|$

$=\left|\mathrm{f}(\mathrm{x}, \mathrm{y})-\mathrm{g}_{0}(\mathrm{x}, \mathrm{y})\right|+\left|\mathrm{g}_{1}(\mathrm{x}, \mathrm{y})\right|$

$\leq\left\|\mathbf{f}-\mathrm{g}_{0}\right\| \infty+\mathrm{k}_{\mathbf{f}}\left\|\mathrm{g}_{1}\right\| \infty$

$=\left\|\mathbf{f}-\mathrm{g}_{0}\right\| \infty+\mathrm{k}_{\mathbf{f}}\left\|\mathrm{g}_{2}-\mathrm{g}_{0}\right\| \infty$.

By (6) and (9) for all $x, y \in U$ with

$\left(\mathrm{f}(\mathrm{x}, \mathrm{y})-\mathrm{g}_{0}(\mathrm{x}, \mathrm{y})\right) \mathrm{g}_{1}(\mathrm{x}, \mathrm{y}) \geq 0$,

$\left|f(x, y)-g_{2}(x, y)\right|=\left|\left(f(x, y)-g_{0}(x, y)\right)-g_{1}(x, y)\right|$

$=\left|f(x, y)-g_{0}(x, y)\right|-\left|g_{1}(x, y)\right|$

$$
\leq\left\|\mathbf{f}-\mathrm{g}_{0}\right\| \infty
$$


$\Rightarrow\left\|\mathbf{f}-\mathrm{g}_{2}\right\| \infty<\left\|\mathbf{f}-\mathrm{g}_{0}\right\| \infty+\mathrm{k}_{\mathbf{f}}\left\|\mathrm{g}_{2}-\mathrm{g}_{0}\right\|_{\infty}$,

$\Rightarrow$ (i) fails. (ii) $\Rightarrow$ (iii) suppose that (ii) holds.

Let $F:\{g \in G:\|g\| \infty=1\} R \rightarrow$ Re the mapping, defined by

$$
F(g)=\min _{x, y \in E\left(f-g_{0}\right)} \frac{\left(f(x, y)-g_{0}(x, y)\right) g(x, y)}{\left\|f-g_{0}\right\|_{\infty}}
$$

Since $G$ is finite dimensional, the set $\{\mathrm{g} \in \mathrm{G}:\|\mathrm{g}\| \infty=1\}$ is compact. Therefore, since by (ii) $\mathrm{F}(\mathrm{g})$ $<0$ for all $\{\mathrm{g} \in \mathrm{G}:\|\mathrm{g}\| \infty=1\}$, there exists a constant $\mathrm{k}_{\mathbf{f}}>0$

Such that $F\left(\frac{g}{\|g\|_{\infty}}\right) \leq-\mathrm{k}_{\mathbf{f}}$ for all $\mathrm{g} \in \mathrm{G}$, which proves (iii)

$\therefore($ iii $) \Rightarrow($ ii $)$ is obvious

Hence the proof of the theorem is complete.

Theorem 3.7. Let $G$ be a finite dimensional subspace of a real 2-Hilbert space $X$. Then for every $x \in X$, there exists a unique best approximation from $\mathrm{G}$.

Proof. Let $(X,\|, \cdot\|$ ) be a 2-Hilbert space and let $\mathrm{G}$ be a finite dimensional subspace of $\mathrm{X}$.

Let $x, y \in X$ and $x \neq y$ then by parallelogram law

$\|x+y, z\|^{2}+\|x-y, z\|^{2}=2\left(\|x, z\|^{2}+\|y, z\|^{2}\right)$.

Let $\|\mathrm{x}, \mathrm{z}\|=\|\mathrm{y}, \mathrm{z}\|=1$.

Then by (10)

$\|\mathrm{x}+\mathrm{y}, \mathrm{z}\|^{2}=4\|\mathrm{x}-\mathrm{y}, \mathrm{z}\|^{2}<4$

$\Rightarrow\left\|\frac{x+y}{2}, z\right\|^{2}<1$

$\Rightarrow \mathrm{X}$ is strictly convex. Therefore, by Theorem 3.2 there exists a unique best approximation to $\mathrm{x}$ $X \backslash G$ from $G$.

Theorem 3.8. Let $G$ be a subspace of a real 2-Hilbert space $X, x \in X \mid G$ and $\mathrm{g}_{0} \in \mathrm{G}$. Then the following statements are equivalent:

(i) The element $g_{0}$ is a best approximation of $x$ from $G$. (ii) For all $g \in G,\left(x-g_{0}, g / z\right)=0 \quad z \in X$ IV (x, G) .

Proof. (ii) $\Rightarrow$ (i). Suppose that (ii) holds and let $g \in G$. Then by (ii) $\|x-g, z\|^{2}-\left\|x-g_{0}, z\right\|^{2}$ $=(\mathrm{x}-\mathrm{g}, \mathrm{x}-\mathrm{g} / \mathrm{z})-\left(\mathrm{x}-\mathrm{g}_{0}, \mathrm{x}-\mathrm{g}_{0} / \mathrm{z}\right)$

$=(\mathrm{x}, \mathrm{x} / \mathrm{z})+(\mathrm{g}, \mathrm{g} / \mathrm{z})-2(\mathrm{x}, \mathrm{g} / \mathrm{z})-(\mathrm{x}-\mathrm{x} / \mathrm{z})-\left(\mathrm{g}_{0}, \mathrm{~g}_{0} / \mathrm{z}\right)+2\left(\mathrm{x}, \mathrm{g}_{0} / \mathrm{z}\right)$

$\geq 0$

$=\left(\mathrm{g}-\mathrm{g}_{0}, \mathrm{~g}-\mathrm{g}_{0} / \mathrm{z}\right)+2\left(\mathrm{x}-\mathrm{g}_{0}, \mathrm{~g}_{0}-\mathrm{g} / \mathrm{z}\right) \geq 0$

$=\left\|\mathrm{g}-\mathrm{g}_{0}, \mathrm{z}\right\|^{2} \geq 0$

That is $\|x-g, z\| \geq\left\|x-g_{0}, z\right\|$ which proves (i) 
(i) $\Rightarrow$ (ii). Suppose that (ii) fails, i.e., there exists a function $g^{\prime} \in G$ such that $\left(\mathrm{x}-\mathrm{g}_{0}, \mathrm{~g}^{\prime}\right) \neq 0$.

$$
\begin{aligned}
& \left\|x-\left(g_{0}+\frac{\left(x-g_{0}, g^{\prime} / z\right)}{\left(g^{\prime}, g^{\prime} / z\right)} g^{\prime} / z\right)\right\|^{2} \\
& =\left\|x-g_{0} / z\right\|^{2}-\frac{\left(x-g_{0}, g^{\prime} / z\right)^{2}}{\left(g^{\prime}, g^{\prime} / z\right)}
\end{aligned}
$$

$<\left\|x-g_{0} / z\right\|^{2}$ Which implies that $\mathrm{g}_{0}$ is not a best approximation of $\mathrm{x}$.

Hence the proof.

Corollary 3.9. Let $\mathrm{G}=\operatorname{span}\left(\mathrm{g}_{1}, \mathrm{~g}_{2}, \cdots, \mathrm{g}_{\mathrm{n}}\right)$ be an $\mathrm{n}$-dimensional subspace of a real 2-Hilbert space $X, x \in X \backslash G$ and $g_{0}=$

statements are equivalent: $\sum_{i=1}^{n} a_{i} g_{i} \in G$. Then the following

(i) The element $\mathrm{g}_{0}$ is a best approximation of $\mathrm{x}$ from $\mathrm{G}$.

(ii) The coefficients $a_{1}, a_{2}, \cdots a_{n}$ satisfy the following system of linear equations

$$
\sum_{i=1}^{n} a_{i}\left(g_{i}, g j / z\right)=(x, g j / z), j=1,2, \cdots, n \text {. }
$$

Proof. The condition $\left(\mathrm{f}-\mathrm{g}_{0}, \mathrm{~g} / \mathrm{z}\right)=0$ in Theorem 3.8 is equivalent to $(\mathrm{f}-\mathrm{g} 0, \mathrm{~g} / \mathrm{z})=0, \mathrm{j}=1,2, \ldots, \mathrm{n}$.

Since $g_{0}=\sum_{i=1}^{n} a_{i} g_{i}, \sum_{i=1}^{n} a_{i}\left(g_{i}, g_{j} / z\right)=\left(f, g_{j} / z\right)$ is equivalent to $\left(\mathrm{f}-\mathrm{g}_{0}, \mathrm{~g}_{\mathbf{j}}\right)=0, \mathrm{j}=1,2, \ldots, \mathrm{n}$.

\section{References}

[1] M.W. Barelt, H.W. McLaughlin, Characterizations of strong unicity in approximation theory, Journal of Approximation Theory, 9 (1973), 255-266.

[2] C. Diminnie, S. Gahler, A. White, Strictly convex 2-normed space, Mathematische Nachrichten, 59 (1974), 319-324.

[3] C. Franchetti, M. Furi, Some c h a r a c t e r i s t i c properties of rea 1 Hilbert spaces,Romanian Journal of Pure and Applied Mathematics, 17 (1972), 1045-1048.

[4] R.W. Freese, Y.J. Cho, Geometry of linear 2 -normed spaces, N ov a science publishers, Inc., New York, (2001).

[5] S.Gahler, Linear 2-normierte Raume, Mathematische Nachrichten, 28 (1964),1-43.

[6] I. Singer, On the set of best approximation of an element in a normed linear space, Romanian Journal of Pure and Applied Mathematics, 5 (1960), 383-402.

[7] D.E. Wulbert, Uniquess and differential characterization of approximation from manifolds, American Journal of Mathematics, 18 (1971), 350-366. 